\title{
The presence of persistent coliform and $E$. coli contamination sequestered within the leaves of the popular fresh salad vegetable "Jarjeer / Rocket" (Eruca sativa L.).
}

\author{
Dennis J. Russell ${ }^{1 *}$; Sarah Abdul Majid ${ }^{2}$ and Daniel Tobias ${ }^{3}$ \\ 1- Department of Biology and Chemistry, American University of Sharjah, PO Box \\ 26666, Sharjah, United Arab Emirates. \\ 2- 3512 Lake View Tower, Dubai, United Arab Emirates \\ 3- Department of Biology and Chemistry, American University of Sharjah, PO Box \\ 26666, Sharjah, United Arab Emirates. \\ *Tel: (971) 6-515-2406; Fax: (971) 6-515-2450; E-mail: drussell@aus.edu
}

\begin{abstract}
Tests of Jarjeer/rocket (Eruca sativa L.) salad greens after multiple washings in water and mild disinfectant revealed a significant number of sequestered total coliforms and E. coli remained in the fresh greens. Presumptive tests of 64 locally purchased fresh jarjeer greens resulted in finding $100 \%$ of the samples were contaminated by coliforms and E. coli. Jarjeer greens had 2,509,273 CFU/g and $224,250 \mathrm{E}$. coli/g when washed once. Washing the greens three times reduced the number of CFU by $95 \%$ and $E$. coli by $83 \%$, but E. coli counts remained high 9,741 / $\mathrm{g}$ or 292,230 per $30 \mathrm{~g}$ normally eaten portion. After macerating the thrice washed jarjeer the number of CFU increased to $2,129,774 / \mathrm{g}$ and E. coli $56,292 / \mathrm{g}$, which indicated the bacteria are sequestered in the leaves and could not be washed off. Disinfection with diluted chlorine bleach reduced CFU by $68 \%$ and E. coli by $84 \%$, but upon maceration CFUs increased from 42,059/g to 833,812/g and E. coli from $5 / \mathrm{g}$ to $2,150 / \mathrm{g}$, which indicates washing with a disinfectant cannot rid the greens of coliforms. Counts on parsley and lettuce were significantly lower than on jarjeer. Results indicate there is sequestered fecal contamination of fresh jarjeer salad greens that remained on and inside epidermal cells even after multiple washings. These data show that there is probably a persistent health threat when eating these fresh salad greens, but further testing for the presence of Salmonella and other pathogens is required.
\end{abstract}

Keywords: coliform, E. coli, jarjeer, rocket, Eruca sativa, parsley, lettuce, fecal, contamination, United Arab Emirates, Dubai, Sharjah, IDEXX, sequestered

\section{INTRODUCTION}

The mustard salad greens (Eruca sativa L.), which are grown on United Arab Emirates (UAE) produce farms, are called "jarjeer" or "jarjir" in Arabic and "rocket" in English or "roquette"in French, are a favorite and popular part of the traditional Arab meal (Figure 1). These greens were tested for total coliforms and compared to parsley and romaine lettuce from local stores. Prior to formal testing, presumptive tests of jarjeer/rocket greens were conducted at the
American University of Sharjah, United Arab Emirates (UAE), and consistently yielded $100 \%$ coliform and Escherichia coli Castellani and Chalmers presence and further tests using IDEXX always showed high levels of total coliforms and E. coli contamination. Jarjeer is usually eaten without being cooked, which makes it and other salad greens the most likely food source from which people could be infected by enteric pathogens (Davis and Kendal, 2007). Jarjeer greens are grown rapidly from seed to a height of $10-30 \mathrm{~cm}$, 
uprooted and bundled by hand before being transported directly to grocery stores and restaurants throughout the UAE and was the primary subject tested.

Although the most common strains of $E$. coli are not pathogenic and serve a useful role in the digestive tracts of mammals, their presence in food or water indicates fecal contamination and the likelihood that Salmonella, Shigella and possibly rotavirus and other pathogens including E. coli $\mathrm{O} 157: \mathrm{H} 7$ strain could be present and ingested (Ilic et al. 2008; Lynch et al. 2006). Sometimes E. coli $\mathrm{O} 157: \mathrm{H} 7$ is found in small numbers in mammal feces, which often contaminate vegetables fertilized with improperly treated or raw manure. In the United States, E.coli has been reported in small amounts from spinach greens, lettuce, parsley, alfalfa sprouts and other vegetables, but neither coliforms nor $E$. coli have been reported from the very popular jarjeer or other freshly eaten greens in the Middle-east. The U.S. Food and Drug Administration has not determined what a safe level of coliforms or $E$. coli could be on vegetables, but it should be very low considering that a 10 cell dose could initiate an infection and cause a serious illness, especially in children (Lynch, et al. 2006). The Brazilian government has established the upper acceptable limit for fecal coliforms on vegetables at $200 \mathrm{CFU} / \mathrm{g}$ (Simoes, et al. 2001). E. coli numbers on vegetables is considered unacceptable when $25 \%$ of the vegetables tested are shown to be contaminated, while, in comparison, swimming pool water is contaminated if 1 of 3 tests are positive for E. coli and drinking water is required to be entirely free of $E$. coli to be safe. Clean vegetable greens for the consumer, along with precautionary farming, hygienic handling measures and accurate reporting of coliform and E.coli related enteric illnesses, are necessary to protect the public from vegetables that could cause sporadic gastrointestinal epidemics (Advik et al. 2006; Simoes, et al. 2001). The purpose of this paper is to present the results of systematically tested, locally grown Eruca sativa "jarjeer", for the presence and numbers of coliforms and $E$. coli and to compare the results to parsley (Petroselium cripum (P.Mill.) Nyman ex A.W.Hill) and romaine lettuce (Latuca sativa L.). The hypothesis tested is: after three washings and/or disinfection a significant number of coliforms remain sequestered on or in the leaf tissue.

\section{MATERIALS AND METHODS}

Initial presumptive tests were done on bundled jarjeer greens purchased at random from 64 local stores in the United Arab Emirates, and more thorough tests were done on random samples taken from 20 of these stores. These greens came to the stores as leaves attached to a small tap root with 20-30 bundled together with a rubber band. Each bundle was weighed and the plantlets counted. Before doing presumptive tests on the greens, three replicates $10 \mathrm{~g}$ each were removed from each bundle for further testing. The remaining bulk of each bundle, was gently washed in $1 \mathrm{~L}$ sterile water for five minutes, $100 \mathrm{ml}$ wash water removed and presumptive tests performed using the American Public Health Association approved IDEXX method (IDEXX Laboratories, Inc., Maine, USA; Clesceri et al. 1999). Microscopic examination of fresh sectioned leaves was also performed.

Replicate samples were washed for 10 minutes in $1 \mathrm{~L}$ sterile water, then transferred into another $1 \mathrm{~L}$ sterile water and rinsed again for 10 minutes and washed again for a third time in $1 \mathrm{~L}$ sterile water for 10 minutes. After the third wash the greens were placed into a fourth $1 \mathrm{~L}$ sterile water and macerated in a blender for 1 minute. The macerated samples represent a person chewing and the ingestion of any remaining sequestered bacteria.

The first wash water was sampled and diluted, $0.05 \mathrm{ml}$ wash water into $99.95 \mathrm{ml}$ sterile water, the second and third wash water was diluted 0.5 wash water into $99.5 \mathrm{ml}$ sterile water and all were tested using IDEXX Quanti-tray 12000. The IDEXX method further divides the $100 \mathrm{ml}$ sample into 97 subsamples which gives a most probable number with a statistical confidence of $95 \%$. Appropriate dilutions were used on the successive washes to bring the numbers of CFUs 
down to within the ability of IDEXX to accurately detect and enumerate. Final counts from these dilutions were calculated back to the washed samples to arrive at the total $\mathrm{CFU} / \mathrm{g}$ jarjeer and $E$. coli/g. Parsley and romaine lettuce greens were tested in the same manner for comparison.

In the second test, jarjeer, parsley and romaine lettuce were treated with a mild solution of commercial chlorine bleach diluted $5 \mathrm{ml}$ into $1 \mathrm{~L}$ sterile water (Chlorox brand was used to assure uniform strength and consistent quality) (Niemira, 2007). The greens were first washed for 10 minutes in $1 \mathrm{~L}$ sterile water, which was analyzed for total coliforms and E. coli, then transferred to $1 \mathrm{~L}$ diluted chlorine bleach water and disinfected for 10 minutes. This was followed by a 10 minute rinse in $2 \mathrm{~L}$ sterile water to remove the residual chlorine. They were then transferred to another1L sterile water and washed for 10 minutes. Finally, each sample was placed into $1 \mathrm{~L}$ sterile water and macerated for one minute in a sterile blender.

This water was diluted and tested as before. Statistics were performed using Minitab16, Minitab Inc. State College and Rao (1998).

\section{RESULTS}

The average weight of a bundle of jarjeer was $197.4 \pm 43.6 \mathrm{~g}$ and the dry soil collected was $2.9 \pm 1.2 \mathrm{~g}$ soil $/ 100 \mathrm{~g}$ jarjeer. Presumptive tests on the 64 store samples resulted in $100 \%$ coliform and E. coli positive. Microscopic examination after the leaves were washed resulted in finding actively swimming spirillum, large flagellated bacilli $(0.7 \quad$ x $2.5 \mu \mathrm{m})$, encapsulated diplococci and typical cocci and bacilli. Most were located inside of the epidermal cells and on the surface of the epidermis. No bacteria were seen in the mesophyll or vascular tissue.

Two of the 20 jarjeer samples resulted in Colony Forming Units (CFU) that were too high to count (ca $9,000,000 / \mathrm{g}$ ) with the IDEXX method so were not included in Table 1 . This indicates that some of the jarjeer greens are extremely contaminated with bacteria, considering one gram is the size of only one small leaf. IDEXX results from the first wash of the remaining 18 samples showed an average of 1,810,977 CFUs/g and 224,250 E. coli/g jarjeer (Tables 1 \& 2 ) and represents a conservative estimate of the bacteria removed from the greens when washed only once. Results from jarjeer greens washed three times gave an estimate of how effective washing with water alone would be to remove the coliforms (Tables $1 \& 2$ ).

Table 1: Coliform units (CFU/g) on jarjeer washed three times and then macerated to reveal sequestered bacteria. Each data point is within $95 \%$ confidence.

\begin{tabular}{|c|c|c|c|c|}
\hline Samples & Wash \#1 & Wash \#2 & Wash \#3 & Macerated \\
\hline A & $\mathbf{4 , 1 2 3 , 8 1 0}$ & $\mathbf{1 , 8 8 7 , 0 1 2}$ & $\mathbf{3 , 1 0 6 , 2 0 0}$ & $\mathbf{4 , 8 3 9 , 2 0 0}$ \\
\hline C $^{*}$ & $\mathbf{1 6 6 , 8 4 8}$ & $\mathbf{4 0 , 6 1 0}$ & $\mathbf{2 5 , 5 5 9}$ & $\mathbf{2 7 6 , 7 4 6}$ \\
\hline D & $\mathbf{5 , 8 7 4 , 2 3 7}$ & $\mathbf{4 4 0 , 5 6 7}$ & $\mathbf{2 7 6 , 7 4 6}$ & $\mathbf{8 , 2 0 3 , 2 5 4}$ \\
\hline E & $\mathbf{4 1 6 , 7 0 0}$ & $\mathbf{3 4 9 , 6 5 5}$ & $\mathbf{6 , 5 1 7}$ & $\mathbf{1 5 0 , 0 6 9}$ \\
\hline F & $\mathbf{7 7 0 , 0 0 0}$ & $\mathbf{2 5 7 , 3 2 5}$ & $\mathbf{1 4 9 , 4 4 9}$ & $\mathbf{1 , 3 4 1 , 0 9 0}$ \\
\hline G & $\mathbf{1 , 2 0 3 , 3 0 0}$ & $\mathbf{3 6 8 , 3 2 0}$ & $\mathbf{1 1 , 3 2 5}$ & $\mathbf{9 3 , 5 5 4}$ \\
\hline H & $\mathbf{2 , 7 3 2 , 9 0 0}$ & $\mathbf{4 5 8 , 5 0 8}$ & $\mathbf{3 1 , 1 8 3}$ & $\mathbf{1 6 5 , 2 7 0}$ \\
\hline I & $\mathbf{8 3 7 , 0 4 0}$ & $\mathbf{3 8 3 , 3 6 4}$ & $\mathbf{1 2 6 , 5 1 0}$ & $\mathbf{2 1 5 , 0 6 7}$ \\
\hline J & $\mathbf{3 , 5 7 5 , 4 1 1}$ & $\mathbf{1 , 0 2 8 , 7 4 3}$ & $\mathbf{8 2 , 2 9 4}$ & $\mathbf{1 5 1 , 9 6 1}$ \\
\hline K & $\mathbf{1 , 5 5 5 , 5 4 5}$ & $\mathbf{6 8 4 , 4 3 9}$ & $\mathbf{5 2 0 , 1 7 4}$ & $\mathbf{9 8 8 , 3 3 1}$ \\
\hline L & $\mathbf{1 , 7 2 5 , 2 0 5}$ & $\mathbf{5 3 7 , 6 8 9}$ & $\mathbf{5 6 , 8 6 6}$ & $\mathbf{7 4 , 3 0 9}$ \\
\hline M & $\mathbf{1 , 7 9 5 , 6 2 2}$ & $\mathbf{2 2 8 , 8 3 8}$ & $\mathbf{2 2 , 8 8 4}$ & $\mathbf{1 3 7 , 3 0 4}$ \\
\hline N & $\mathbf{1 , 7 5 9 , 7 0 9}$ & $\mathbf{8 5 7 , 7 2 6}$ & $\mathbf{2 3 9 , 4 0 0}$ & $\mathbf{7 , 5 6 2 , 1 1 9}$ \\
\hline O* & $\mathbf{5 1 6 , 9 9 1}$ & $\mathbf{2 1 3 , 6 7 8}$ & $\mathbf{2 0 , 2 9 8}$ & $\mathbf{1 5 , 2 4 4}$ \\
\hline Q & $\mathbf{1 , 5 5 3 , 1 0 0}$ & $\mathbf{3 7 7 , 4 0 2}$ & $\mathbf{5 4 , 8 0 9}$ & $\mathbf{6 5 , 8 3 0}$ \\
\hline R & $\mathbf{2 , 4 1 9 , 2 2 1}$ & $\mathbf{4 3 5 , 4 6 0}$ & $\mathbf{9 8 , 7 7 8}$ & $\mathbf{4 4 9 , 8 7 6}$ \\
\hline S & $\mathbf{1 , 4 1 3 , 2 3 4}$ & $\mathbf{9 4 2 , 1 5 6}$ & $\mathbf{1 0 4 , 6 8 4}$ & $\mathbf{1 8 4 , 6 5 5}$ \\
\hline T & $\mathbf{1 5 8 , 5 0 0}$ & $\mathbf{4 9 , 5 3 1}$ & $\mathbf{5 4 , 5 2 1}$ & $\mathbf{9 3 , 5 0 0}$ \\
\hline Total & $\mathbf{3 2 , 5 9 7 5 9 3}$ & $\mathbf{9 , 5 4 1 , 0 2 3}$ & $\mathbf{2 , 9 8 8 , 1 9 7}$ & $\mathbf{2 5 , 0 0 7 , 3 7 9}$ \\
\hline Average & $\mathbf{1 , 8 1 0 , 9 7 7}$ & $\mathbf{5 3 0 , 0 5 7}$ & $\mathbf{1 6 6 , 0 1 1}$ & $\mathbf{1 , 3 8 9 , 2 9 9}$ \\
\hline SD & $\pm \mathbf{1 , 4 9 4 , 0 3 6}$ & $\mathbf{4 3 3 7 , 3 9 7}$ & $\pm 266,773$ & $\pm 2,616,780$ \\
\hline
\end{tabular}

*Values of samples B and P exceeded the limits of IDEXX and were removed.

Table 2: E. coli/g on jarjeer washed three times and then macerated to reveal sequestered bacteria. Each data point has $95 \%$ confidence.

\begin{tabular}{|c|c|c|c|c|}
\hline Samples & Wash \#1 & Wash \#2 & Wash \#3 & Macerated \\
\hline A & 13,630 & 63 & 0 & 2000 \\
\hline B & 364 & 0 & 364 & 746 \\
\hline C & 13,559 & 16,949 & 994 & 5,509 \\
\hline D & 29,153 & 1,050 & 0 & 100 \\
\hline E & 271,241 & 355 & 305 & 3,345 \\
\hline F & 547,500 & 30,809 & 6,166 & 67,766 \\
\hline G & 920,800 & 60,645 & 6,949 & 74,190 \\
\hline H & $1,046,200$ & 121,303 & 14,858 & 31,206 \\
\hline I & 137,741 & 632 & 103 & 561 \\
\hline J & 225,546 & 146,605 & 16,127 & 20,965 \\
\hline K & 198,818 & 143,149 & 27,109 & 62,555 \\
\hline L & 2,509 & 4 & 0 & 12 \\
\hline M & 204 & 12 & 0 & 2,365 \\
\hline N & 2,360 & 1,143 & 187 & 1,112 \\
\hline O & 10,689 & 13,465 & 8,967 & 18,652 \\
\hline P & 920,800 & 445,100 & 112,387 & 730,516 \\
\hline Q & 12,439 & 3,569 & 43 & 1,276 \\
\hline R & 129,540 & 989 & 254 & 8,790 \\
\hline S & 1,874 & 437 & 8 & 678 \\
\hline T & 36 & 0 & 0 & 93,500 \\
\hline Total & $4,485,003$ & 986,279 & 194,821 & $1,125,844$ \\
\hline Average & 224,250 & 49,314 & 9,741 & 56,292 \\
\hline SD & $\pm 346,828$ & $\pm 105,453$ & $\pm 25,253$ & $\pm 161,396$ \\
\hline
\end{tabular}

The second wash water removed $54 \pm 26 \%$ of the CUFs and $74 \pm 33 \%$ of the $E$. coli when compared to the initial wash and a $85 \pm 17 \%$ CFU reduction and a $94 \pm 18 \%$ E. coli reduction, when compared 
to the third wash. The reduction from the initial wash to the third wash statistically significant $(\mathrm{P}=0)$ for $\mathrm{CFU}$ and $(\mathrm{P}=0.005)$ for $E$. coli even with large differences between samples.

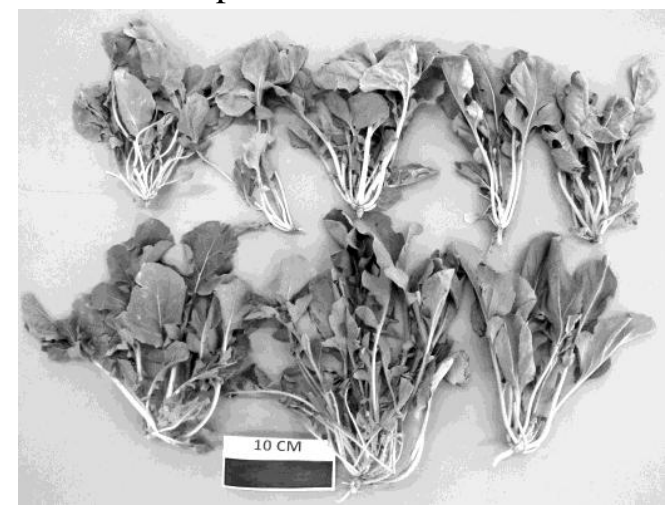

Fig. 1: The mustard salad greens (Eruca sativa $\mathrm{L}$.), which are grown on United Arab Emirate (UAE) produce farms, called "jarjeer" or "jarjir" in Arabic and "rocket" in English or "roquette"in French, are a favorite and popular salad item in traditional Arab meals.

After being washed three times there should be fewer bacteria in the next wash even when macerated unless the bacteria are being held tightly to the plant or sequestered in the leaf cells and only then would we expect the bacteria numbers to be the same or increase. However, additional release of 2,129,774 CFU/g was significant at $90 \%$ and almost significant at $95 \%(\mathrm{P}=0.052$ at $95 \%)$, but regardless of the statistics, there should have been a decrease in CFU. The additional release of 56,292 E. coli/g after the washed jarjeer was macerated was an increase, but it was not statistically significant $(P=0.15)$ from the average for the third washing, but again, there should have been a decrease not an increase (Tables $1 \& 2$; Figs. $2 \& 3$ ).

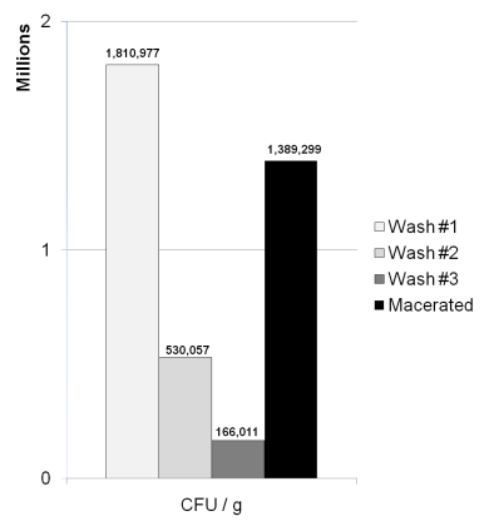

Fig. 2: Coliform units (CFU / g) on jarjeer washed three times and macerated to release the sequestered bacteria.

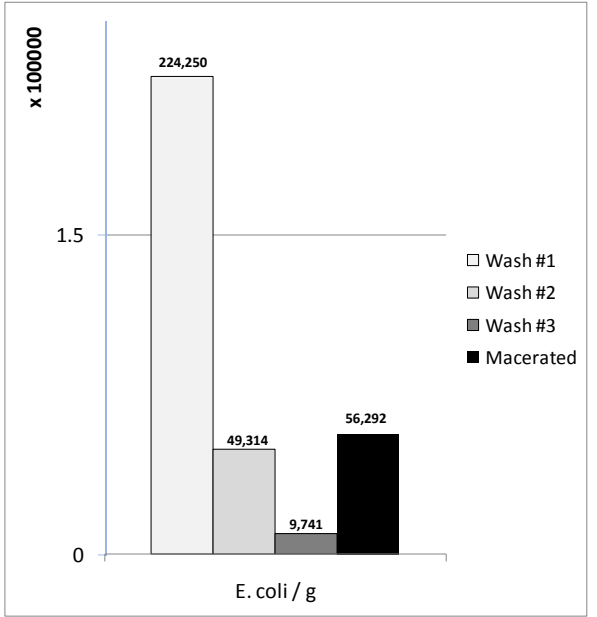

Fig. 3: E. coli / g on jarjeer washed three times and macerated to release the sequestered bacteria.

Significant differences for E. coli were present between samples (from only $36 \mathrm{E}$. coli/g to $1,046,200 \mathrm{E}$. coli/g) which shows contamination is not consistent in strength, even if it is consistently present. There was also an average $312 \pm 228 \%$ increase in CFUs and 5,979 $\pm 2,168 \%$ increase in E. Coli after maceration. The most important feature of the data for $E$. coli was that the third washing often brought the E. coli down to zero, but in each sample more $E$. coli were released upon maceration.

After being washed in a mild disinfectant for 5 minutes, the surface of jarjeer still had a final total viable coliform count of $42,059 \mathrm{CFU} / \mathrm{g}$ after 3 washes with $833,812 \mathrm{CFU} / \mathrm{g}$ released by maceration (Table 3).

Table 3: Coliforms and E. coli on jarjeer disinfected with mild bleach, rinsed, washed and then macerated to release the sequestered bacteria. Each data point is within $95 \%$ confidence.

\begin{tabular}{|l|c|c|c|c|c|c|}
\hline & \multicolumn{3}{|c|}{ CFUs/g } & \multicolumn{3}{c|}{ E. coli/g } \\
\hline Samples & Wash \#1 & Wash \#3 & Macerated & $\begin{array}{l}\text { Wash } \\
\# 1\end{array}$ & $\begin{array}{l}\text { Wash } \\
\# 3\end{array}$ & Macerated \\
\hline A & 235,281 & 78,842 & $2,439,200$ & 702 & 0 & 0 \\
\hline B & 475,473 & 33,649 & 35,895 & 10,000 & 0 & 2,105 \\
\hline C & 43,323 & 13,686 & 26,341 & 29 & 5.0 & 45 \\
\hline Total & 754,077 & 126,177 & $2,501,436$ & 10,731 & 5.0 & 2,150 \\
\hline Average & 251,359 & 42,059 & 833,812 & 3,577 & 1.7 & 717 \\
\hline SD & $\pm 216,523$ & $\pm 33,382$ & $\pm 1,390,315$ & $\pm 5,573$ & \pm 2.9 & $\pm 1,203$ \\
\hline
\end{tabular}

Disinfecting with mild chlorine bleach reduced the numbers of $\mathrm{CFU}$ and $E$. 
coli on the surface of the jarjeer leaves, but did not reach the sequestered bacteria living inside the deteriorating epidermal cells. Disinfection reduced E. coli from $3,577 / \mathrm{g}$ to $1.7 / \mathrm{g}$, but $717 / \mathrm{g}$ were released upon maceration. The sample sizes for the disinfectant part of the study (jarjeer, parsley and romaine lettuce) were too small and the variation too great for accurate statistics, so lends itself to descriptive analysis only.

Parsley greens and romaine lettuce also contained sequestered coliforms, but were less contaminated with E. coli than jarjeer (Fig. 6). Parsley had much lower CFUs $22,935 / \mathrm{g}$, and lower E. coli 4,074/g (Table 4) than romaine lettuce, CFUs $71,048 / \mathrm{g}$; E. coli 83,958 (Table 5).

Table 4: Coliforms and E. coli on parsley washed three times and then macerated to release the sequestered bacteria. Each data point is within $95 \%$ confidence.

\begin{tabular}{|l|r|r|r|r|}
\hline & \multicolumn{5}{|c|}{ CFU's/g } \\
\hline Samples & Wash \#1 & Wash \#2 & Wash \#3 & Macerated \\
\hline A & $\mathbf{2 0 2 , 7 7 8}$ & $\mathbf{6 1 , 6 3 0}$ & $\mathbf{4 4 , 3 7 0}$ & $\mathbf{7 3 5 , 6 6 7}$ \\
\hline B & $\mathbf{1 9 9 , 0 9 1}$ & $\mathbf{1 3 2 , 8 7 3}$ & $\mathbf{5 2 , 7 2 7}$ & $\mathbf{6 8 , 3 4 4}$ \\
\hline Total & $\mathbf{4 0 1 , 8 6 9}$ & 194,503 & $\mathbf{9 7 , 0 9 7}$ & $\mathbf{8 0 4 , 0 1 1}$ \\
\hline Average & $\mathbf{2 0 0 , 9 3 5}$ & $\mathbf{9 7 , 2 5 2}$ & $\mathbf{4 8 , 5 4 9}$ & $\mathbf{4 0 2 , 0 0 6}$ \\
\hline SD & $\pm \mathbf{1 , 8 4 4}$ & $\pm 35,622$ & $\pm 4,179$ & $\pm 333,662$ \\
\hline \multicolumn{5}{|c|}{ E. coli/g } \\
\hline A & $\mathbf{4 , 0 7 4}$ & $\mathbf{0}$ & $\mathbf{0}$ & $\mathbf{3 7 0}$ \\
\hline B & $\mathbf{0}$ & $\mathbf{0}$ & $\mathbf{0}$ & $\mathbf{0}$ \\
\hline Total & $\mathbf{4 , 0 7 4}$ & $\mathbf{0}$ & $\mathbf{0}$ & $\mathbf{3 7 0}$ \\
\hline Average & $\mathbf{2 , 0 3 7}$ & $\mathbf{0}$ & $\mathbf{0}$ & $\mathbf{1 8 5}$ \\
\hline SD & $\pm 2,037$ & \pm 0 & $\pm \mathbf{0}$ & \pm 185 \\
\hline
\end{tabular}

Table 5: Coliforms and E. coli on romaine lettuce washed three times and then macerated to release the sequestered bacteria. Each data point is within $95 \%$ confidence.

\begin{tabular}{|l|r|r|r|r|}
\hline & \multicolumn{4}{|c|}{ CFU's/g } \\
\hline Samples & Wash \#1 & Wash \#2 & Wash \#3 & Macerated \\
\hline A & $\mathbf{8 0 , 5 3 6}$ & $\mathbf{2 1 , 2 4 6}$ & $\mathbf{6 , 2 6 1}$ & $\mathbf{7 3 5 , 6 6 7}$ \\
\hline B & $\mathbf{8 4 , 5 1 6}$ & $\mathbf{2 5 , 6 2 5}$ & $\mathbf{1 4 , 2 1 9}$ & $\mathbf{6 8 , 3 4 4}$ \\
\hline Total & $\mathbf{1 6 5 , 0 5 2}$ & $\mathbf{4 6 , 8 7 1}$ & $\mathbf{2 0 , 4 8 9}$ & $\mathbf{1 1 8 , 2 8 6}$ \\
\hline Average & $\mathbf{8 2 , 5 2 6}$ & $\mathbf{2 3 , 4 3 6}$ & $\mathbf{1 0 , 2 4 0}$ & $\mathbf{5 9 , 1 4 3}$ \\
\hline SD & $\mathbf{1 1 , 9 9 0}$ & $\pm 2,189$ & $\pm \mathbf{3 , 9 7 9}$ & $\pm 8,701$ \\
\hline \multicolumn{5}{|c|}{ E. coli/g } \\
\hline A & $\mathbf{5 7 , 5 8 0}$ & $\mathbf{4 , 5 8 0}$ & $\mathbf{0}$ & $\mathbf{5 8 0}$ \\
\hline B & $\mathbf{3 , 4 2 2}$ & $\mathbf{9 6 9}$ & $\mathbf{1 , 9 6 8}$ & $\mathbf{4 , 5 3 2}$ \\
\hline Total & $\mathbf{6 1 , 0 0 2}$ & $\mathbf{5 , 5 4 9}$ & $\mathbf{1 , 9 6 8}$ & $\mathbf{5 , 1 1 1}$ \\
\hline Average & $\mathbf{3 0 , 5 0 1}$ & $\mathbf{2 , 7 7 5}$ & $\mathbf{9 8 4}$ & $\mathbf{2 , 5 5 6}$ \\
\hline SD & $\pm 27,079$ & $\pm 1,806$ & \pm 984 & $\pm 1,976$ \\
\hline
\end{tabular}

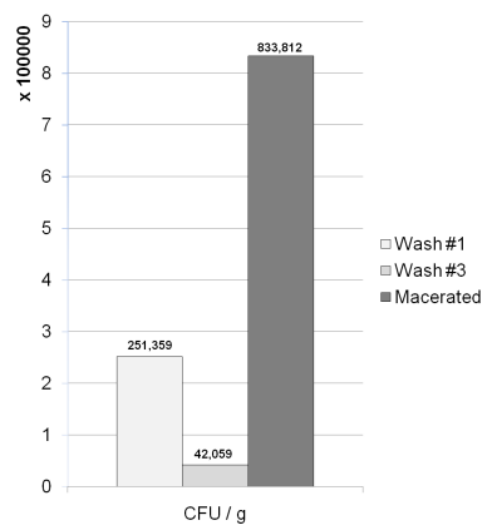

Fig. 4: Coliforms on jarjeer disinfected with mild bleach, rinsed, washed and then macerated to release the sequestered bacteria.

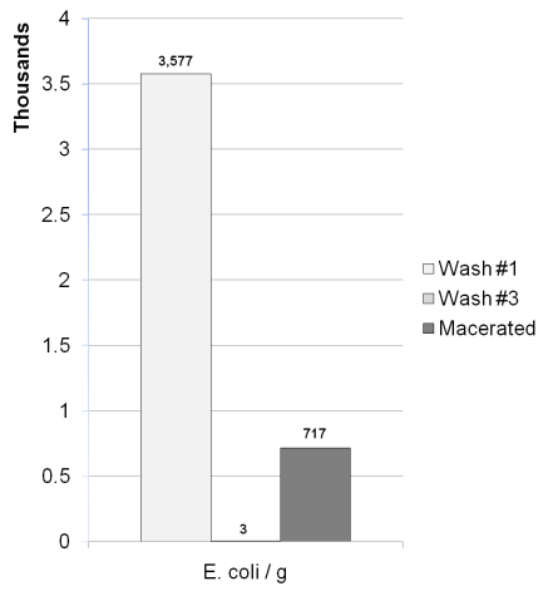

Fig. 5: E. coli on jarjeer disinfected with mild bleach, rinsed, washed and then macerated to release the sequestered bacteria.

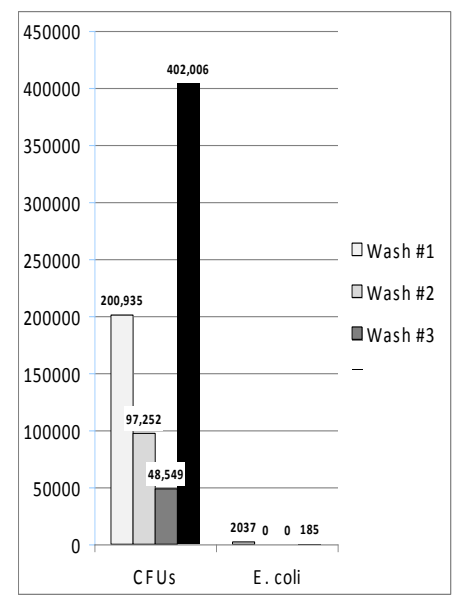

Fig. 6: Coliforms and E. coli on parsley washed three times and then macerated to reveal sequestered bacteria.
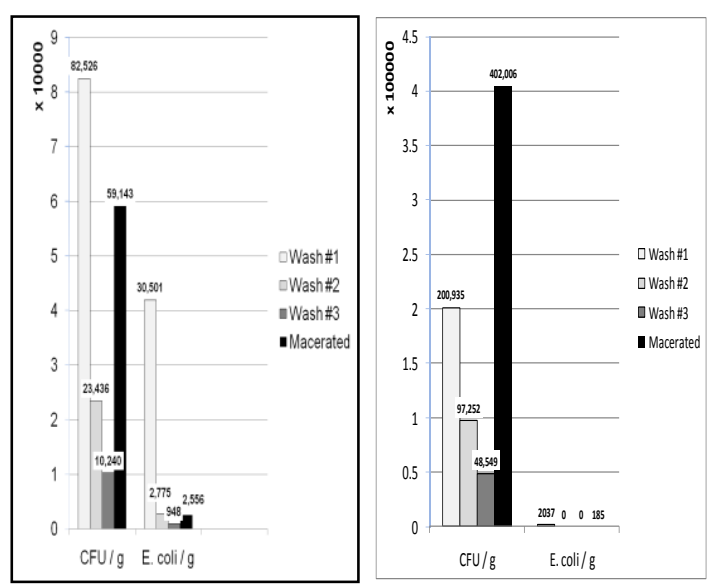

Fig. 7: Coliforms and E. coli on romaine lettuce washed three times and then macerated to release the sequestered bacteria. 


\section{DISCUSSION}

Soil was present on some of the samples, but due to the fact that produce managers often washed the jarjeer to revive its freshness, this reduced the soil content as well as the CFU and E. coli counts, before we began our tests. This fact greatly influenced the standard deviation of our data and the results reflected this fact by showing statistically significant differences between the individual samples (Table 1). The first wash water was above 9,000,000 CFUs/g at two stores and less than 200,000 at other stores (Table 1). However, every store sample showed the same clear and obvious trend from being initially highly contaminated, to having a significant drop in bacteria after three washes and a significant increase in bacteria after maceration (Fig. 1 \& 2). These tests showed that jarjeer greens were always highly contaminated with coliforms and $E$. coli.

Usually the greens are only washed once before being eaten, and a person usually eats about $30 \mathrm{~g}$ (one leaf weighs $1-2 g$ ), but our results indicate that even after washing the greens three times a person would be ingesting >14,897,580 CFUs and > 292,230 E. coli during a meal, plus the bacteria that are still sequestered in the leaves. This is far in excess of the 200 CFU/100g required by Brazilian inspection to be declared suitable to eat. Every sample of jarjeer we tested would be condemned according to Brazilian standards (Simoes et al. 2001).

Niemira (2007) has reported that organisms can remain firmly attached to spinach leaves and be sequestered inside tissue portions of the leaves and thus escape being cleansed from the plant. Our experiments showed that sequestered coliforms made up a significantly important amount of the bacteria contaminating jarjeer greens.

If the bacteria were only on the surface one would expect the numbers to decrease between a third washing and maceration. However, note Table 2, sample T, where all the surface $E$. coli had been removed by washing, but 93,500 $E$. coli/g were released when macerated indicating the presence of sequestered bacteria. This also greatly influenced the variation in that column and shows that there are significant differences between samples. Therefore, regardless of how clean the leaves appear on the outside or after several washings a person would still be ingesting at least $63,893,220$ CFUs and $1,688,760$ E. coli/30g portion during a meal and this is in addition to the number of bacteria remaining on the outside of the leaves after only one wash.

Disinfecting jarjeer greens with mild chlorine bleach solution should have reduced the number of bacteria on and in the leaves to zero, but it did not reduce the number of bacteria sequestered within the epidermal cells. When the disinfected leaves were macerated an additional 833,812 CFUs/g and 717 E. coli/g jarjeer were released (Table 3 and Figs. 4 \& 5) bringing the total to $25,014,360 \mathrm{CFUs} / 30 \mathrm{~g}$ and 21,510 E. coli/30g ingested portion. The number of $E$. coli a person would ingest from well washed and disinfected jarjeer leaves would be 2,000 times higher than is reported necessary to cause an infection (Niemira, 2007; Froeder, et al. 2007) and is 107 times the limit allowed by the Brazilian government (Simoes, et al. 2001).

Parsley greens and romaine lettuce from the same grocery stores were tested as a control and as a quick comparison to jarjeer greens. The samples were small, but the data show that both vegetables were also contaminated with fecal coliforms and E. coli. Similar contamination levels to those on jarjeer were expected on parsley and lettuce, since all are grown on the same farms and are often placed together in the stores, but jarjeer contamination was higher. Crosscontamination between jarjeer and other greens (mint, coriander, spring onions) that jarjeer comes into contact with in the market is also likely occurring.

Cross-contamination between jarjeer and other vegetables is inevitable when jarjeer is prepared in a kitchen. It was necessary to be extra cautious when handling jarjeer in the laboratory to prevent cross-contamination. Replicate wash samples and blank water controls had to be separated from each other by $500 \mathrm{~cm}$ and the person weighing the jarjeer 
needed to be different from the persons placing samples into the wash water. We observed that restaurants wash jarjeer and other greens together in the same sink before being served. Therefore, other, relatively clean vegetables, could become contaminated with coliforms from the jarjeer greens (Fonseca and Ravishankar, 2007).

Our hypothesis, that few or no coliforms would be present on fresh jarjeer greens, parsley and lettuce, proved to be false, especially as related to jarjeer. The hypothesis that bacteria remain sequestered within and on the epidermal leaf tissues even after being washed proved to be correct and to be a significant source of ingested coliforms when eaten. Jarjeer greens are highly contaminated with coliforms at the time of purchase and remain contaminated even after being washed prior to being served.

Contamination of jarjeer most likely occurs on the farm, especially if raw or poorly composted manure is used to fertilize the produce and if untreated liquid manure is used for irrigation or as a foliage spray. Reducing the exposure of jarjeer and other greens to raw manure or poorly treated irrigation water would greatly reduce contamination, but presently these control measures do not exist. The continued exposure of the public to jarjeer greens with high coliform contamination most certainly poses a public health risk and would be a likely source of infection for a future enteric disease outbreaks. Further tests need to be performed to identify and quantify the presence of Salmonella, other pathogens and parasites on jarjeer leaves.

\section{ACKNOWLEDGMENTS}

Acknowledgement is given to Dr. Hana Sulieman, Mathematics Department, American University of Sharjah, for her critical advice and assistance with the statistical analysis.

\section{REFERENCES}

Avik, M, Speh, D., Jones, A., Busding, K., and Diez-Gonzales, F. 2006. Longitudinal microbiological survey of fresh produce grown by farmers in the upper Midwest. Midwest. J. Food Protection, 69:1928-1936.
CDSC.2005. Enumeration of coliforms and Escherichia coli by IDEXX (Colilert 18) Quanti-tray. Standards Unit, Evaluations and Standards Laboratory, Water Working Group CDSC, specialist and Reference Microbiology Division, Ref. No. W 18i2.3, p. 1-15.

Clesceri, L. S., Greenberg, A. E. and Eaton, A. D. (Eds). 1999. Standard Methods for the Examination of Water and Wastewater, 20 $0^{\text {th }}$ Ed. American Public Health Association. 1325pp.

Davis, J. G. and Kendall, P. 2007. Preventing E. coli from garden to plate. Colorado State University Extension, Nutrition Resources, No. 9.369.

Enumeration of waterborne Escherichia coli with Perifim plates: comparison to standard methods. J. Environ. Qual. 32: 368-373.

Fonseca, J. M. and Ravishankar, S.. 2007. Safer Salads. Am. Sci. 95:494-501.

Froeder, H., Martins, C. G., DeSouza, K. L., Landraf, M., Franco, B. D. G. M., and Destro,

Ilic, S., Odomeru J. and LeJeune, J. T. 2008. Coliforms and prevalence of Esherichia coli and foodborne pathogens on minimally processed spinach in two packing plants. J. Food Prot. 71:2398-2403.

Little, C. and Sagoo, S. 1996. LACORS/HPA Coordinated food liaison group studies: An evaluation of hygiene practices in mobile food vendors in the United Kingdom. Gastrointestinal, Emerging and Zoonotic Infections, Centre for Infections, Health Protection Agency, London. 29pp.

Lynch, M., Painter, J., Woodruff, R. and Braden, C. 2006. Surveillance for food borne disease outbreaks - United States, 1998-2002 (www.edc.gov).

M. T. 2007. Minimally processed vegetable salads: microbial quality evaluation. J. Food Prot. 70:12771280.

Niemira, B. A. 2007. Relative efficacy of sodium hypochlorite wash versus irradiation to inactivate Escherichia coli $\mathrm{O} 157: \mathrm{H} 7$ internalized in leaves of 
romaine lettuce and baby spinach. $J$. Food Prot. 70:2526-2537.

Rao, P. V. 1998. Statistical Research Methods in the Life Sciences, Duxbury Press, Pacific Grove, i-xiv; $889 \mathrm{pp}$.

Simoes, M., Pisani, B., Marques, E. G. L., Prandi, M. A. G., Martini, M. H., Chiarini, P. F. T., Antunes, J. L. F. and
Nogueira, A. P. 2001. Hygienicsanitary conditions of vegetables and irrigation water from kitchen gardens in the municipality of Campias, SP. Braz. J. Microbiol. 32(4): 1-5.

Vail, J. H., Morgan, R., Merino, C. R., Gonzales, F., Miller, R. and Ram, J. L. 2003.

\title{
ARABIC SUMMARY
}

\section{تلوث خلايا أوراق الجرجير (Eruca sativa L.) بيكتيريا الع.colif}

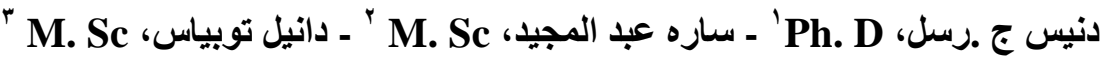

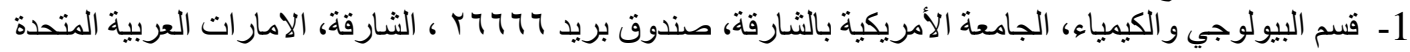

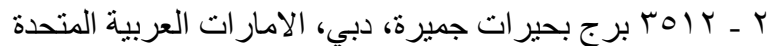

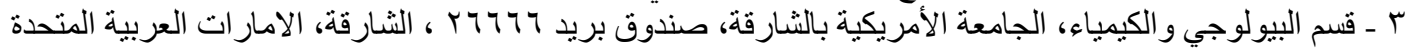

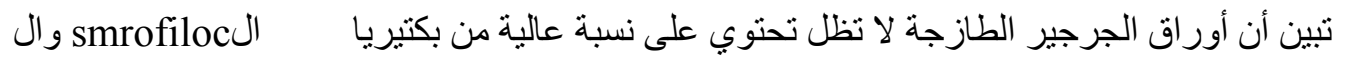 \\ Exoli

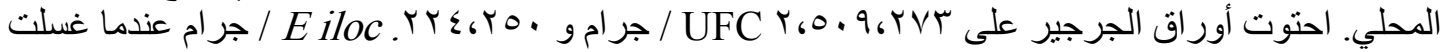

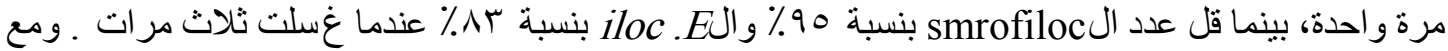

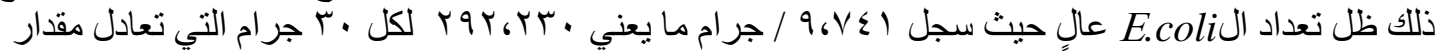

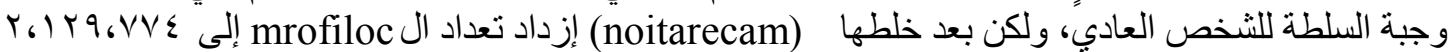

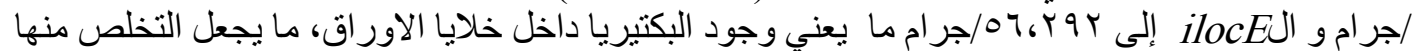

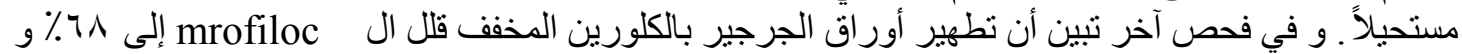

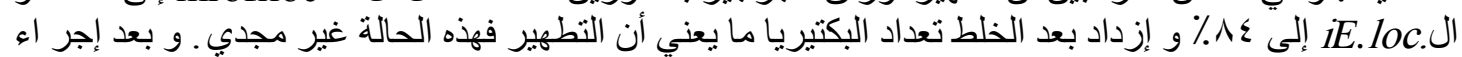

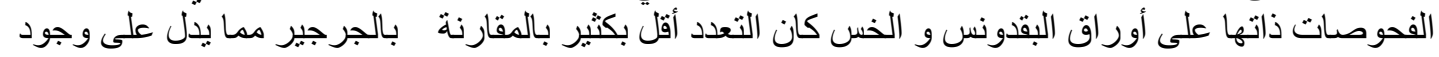

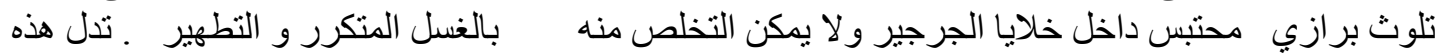

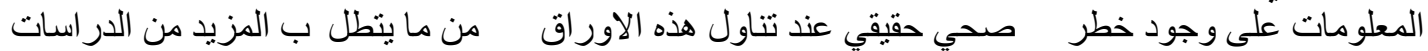 \\ لتحديد أنو اع البكتريا المسبية للمرض الموجودة فيها.
}

